\title{
МОРФЕМНАЯ СТРУКТУРА ГЛАГОЛА В ЯЗЫКЕ НДОНДЕ
}

\author{
Н.В. Громова \\ ИСАА МГУ имени М.В. Ломоносова \\ gromova@iaas.msu.ru \\ M.P. Урб \\ ИСАА МГУ имени М.В. Ломоносова \\ urb72@mail.ru
}

Аннотация: Статья посвящена первичному описанию ранее неисследованного миноритарного языка ндонде и базируется на полевых данных, полученных авторами от информантов в провинции Мтвара на юго-востоке Танзании. Рассматриваются морфемные структуры глагола ндонде и особенности их аффиксальной реализации на аспектно-темпорально-модальном уровне. Данные, полученные с использованием структурного метода описания нового для бантуистики языка, позволят внести вклад в общую проблематику чрезвычайно сложной и многоплановой системы бантуского глагола.

Ключевые слова: миноритарный язык, ндонде, глагол, ТАМ, бантуистика

\section{THE MORPHEMIC STRUCTURE OF THE NDONDE VERB}

\author{
Nelli V. Gromova \\ IAAS, Moscow State University \\ gromova@iaas.msu.ru \\ Monika R. Urb \\ IAAS, Moscow State University \\ urb72@mail.ru
}

Abstract: The article is devoted to the initial description of the previously undescribed minority language Ndonde and is based on field data obtained by the authors from informants in the province of Mtwara in southeastern Tanzania. The morphemic structures of the Ndonde verb and the features of their affixal 
implementation on the aspectual-temporal-modal level are considered. The data collected using the structural method of describing a language new to Bantu studies will make it possible to contribute to the general problems of the extremely complex and multifaceted system of the Bantu verb.

Key words: minority language, Ndonde, verb, TAM, Bantu

\section{1. Введение}

В настоящее время отсутствуют какие-либо, оптимальные или краткие, описания глагола в языке ндонде (банту < нигер-конго), собственно как и других грамматических категорий этого языка ${ }^{1}$, что объясняется слабой изученностью бесписьменных языков Африки в целом и Танзании в частности.

Язык ндонде относится к языкам банту: по классификации языков банту М. Гасри (Guthrie 1948) и уточненной классификации И. Бастен (Bastin 1978) он входит в зону юго-восточных банту в группу Р.20. На карте современной Танзании во всех южных и юго-восточных регионах, входящих в округ Линди от Килвы до Ливале, и за его пределами можно встретить отдельных представителей этой этнической группы, но наиболее компактное их проживание отмечается в районе Начингвеа, где, по данным Атласа языков Танзании, проживает большая часть этноса, около 2229 человек (Atlasi 2009: 42). В настоящее время этно-лингво-географический ареал этноса ндонде значительно сократился и стал дисперсным.

Язык ндонде находится на грани исчезновения: численность говорящих на нем составляла в 2007-2008 гг. всего 2458 человек (Atlasi 2009), и, по нашим наблюдениям, число владеющих языком ндонде продолжает сокращаться. Язык ндонде и культуру этого этноса хранят лишь люди старшего поколения.

При проведении полевого исследования в 2014 г. нам удалось опросить шесть информантов из разных сельских районов южной

${ }^{1}$ Исключением являются две статьи (Громова \& Урб 2015; 2019), где приводится достаточно подробная характеристика именных согласовательных классов в языке ндонде. 
Танзании. Аудиозапись сказок и ответы на анкету позволяют дать предварительное описание структуры глагола в языке ндонде. Морфосинтаксис глагола анализируется с опорой на собственное полевое исследование, а также на методику и теоретические работы отечественных ученых по глаголу в языках Африки (Аксенова \& Tопорова 1990; Виноградов \& Топорова (ред.) 2003).

Структура глагола в языке ндонде, как и в других языках банту, состоит из цепочки аффиксов с различной категориально-грамматической семантикой. В зависимости от конкретной глагольной словоформы количество аффиксов в цепочке может меняться, но соблюдается строго фиксированный порядок следования аффиксов. Так, в предкорневой позиции располагаются аффиксы, выполняющие согласовательную функцию (Pref), за ними следует один из аспектнотемпоральных формантов $\left(\operatorname{Inf}_{1}\right)^{2}$ затем показатель релятива $\left(\operatorname{Inf}_{2}\right)$ и непосредственно предкорневую позицию занимает объектный маркер $\left(\operatorname{Inf}_{3}\right)$. K корню (R) справа примыкают деривативные суффиксы ( $\mathrm{Suf}_{\mathrm{x}}$ ), аспектно-темпоральные суффиксы и завершает цепочку финальный гласный (Fin), который может быть представлен конечным гласным инфинитивной формы или элементом аспектно-темпорального конфикса. Максимальная формула глагола в языках банту может теоретически включать 23 аффикса, но полностью она не реализуется ни в одном языке (Аксенова \& Топорова 1990: 129).

2 Авторы предпочитают использовать укоренившийся в бантуистике со времени издания лингвистической терминологии К. Дока (Doke 1935) термин «инфикс» для обозначения позиции аффиксов между префиксом и корнем глагола. Формула из пяти Pref или более Pref (Аксенова 2003: 43) не отражает семантических различий между префиксом, который является «общим маркером именного класса (в существительном или в зависимых формах» (Поздняков 2017: 169) и аффиксами, характерными только для глагольной системы. Если позицию аффикса перед префиксом принято обозначать как PР (препрефикс), то логичнее позицию аффиксов после префикса обозначать как PostPref / PostP (постпрефикс). Некоторые исследователи во избежание терминологической путаницы предлагают цифровые обозначения позиций аффиксов: 2=In (Initial)=Subject concord, 4=Fo (Formative)=Time/ Aspect/Mood marker и др. (Maganga \& Schadeberg 1992: 97). 


\section{2. Минимальная модель глагольной словоформы в ндонде}

\section{1. Минимальная модель}

Начнем анализ морфемной структуры глагола в языке ндонде с его минимальной модели:

$$
\text { Pref }+\mathrm{R}+\text { Fin }
$$

Эти три элемента являются обязательными для любой глагольной структуры ндонде, как финитной, так и нефинитной. Инфинитив в ндонде образуется следующим образом: kulya > ku-ly-a 'есть / кушать', kulima > ku-lim-a 'пахать'.

По этой же минимальной модели образуется императив:

(1) Hweena!

$\varnothing$-hween-a

Ø-идти-FIN

'Иди!'

(2) Loola!

Ø-lool-a

Ø-смотреть-FIN

'Смотри!'

В данном случае нулевая морфема в позиции Pref выражает значение 2 лица единственного числа.

Оптатив также образуется по минимальной модели:

(3) Aongé.

a-ong-é

3SG-идти-ОРТ

'Пусть он пойдет.'

\section{2. Объектный показатель}

Минимальная формула инфинитива и оптатива, морфологически простейшая, может расширяться в предкорневой позиции за 
счет включения объектного показателя, занимающего позицию $\mathrm{Inf}_{1}$ (модель Pref $+\mathrm{Inf}_{1}+\mathrm{R}+$ Fin; объектные показатели см. в Таблице 1):

(4) kuilya

$k u-i-l y-a$

15 CL-9CL.OBJ-есть-FIN

'есть его (фрукт)'

(5) Amuhaulile.

a-mu-haulil-e

3SG-3SG.OBJ-говорить-оРт

'Пусть он скажет ей.'

Позицию $\operatorname{Inf}_{1}$ может занимать показатель рефлексива, который представлен в языке ндонде морфемой -li-:

(6) kulinowa

ku-li-now-a

15CL-REFL-Гордиться-FIN

'гордиться собой'

Как и во многих языках банту, в языке ндонде позиции объектного показателя и рефлексива или двух объектных показателей несовместимы, в отличие от языка хайя (J.20) (Nurse 1972: 13), допускающего такую возможность, например:

(7) хайя (Nurse 1972: 13)

Twabimuha.

tu-a-bi-mu-ha

1 PL-PST-8CL.OBJ-3SG.OBJ-давать

'Мы дали их ему.' (ebitoke 'бананы')

\section{3. Негативный показатель}

Также модель инфинитива может расширяться за счет негативного показателя, представленного морфемой -nga- в позиции Inf 1 : 
(8) ungayangata

u-nga-yangat-a

15CL-NEG-Помогать-FIN

'не помогать'

(9) ungazilya

u-nga-zi-ly-a

15CL-NEG-10CL.OBJ-есть-FIN

'не есть их (фрукты)'

Таблицุа 1

Субъектные и объектные глагольные показатели

\begin{tabular}{|c|c|c|c|c|c|}
\hline Ед.ч. & $\begin{array}{c}\text { Субъект- } \\
\text { ный } \\
\text { показатель }\end{array}$ & $\begin{array}{c}\text { Объектный } \\
\text { показатель }\end{array}$ & Мн.ч. & $\begin{array}{c}\text { Субъект- } \\
\text { ный } \\
\text { показатель }\end{array}$ & $\begin{array}{c}\text { Объектный } \\
\text { показатель }\end{array}$ \\
\hline 2sG & $n g u-/ n i-$ & $-n g u-$ & $1 \mathrm{PL}$ & $t u-$ & $t u-$ \\
\hline 3SG & $u-$ & $-k u-$ & $2 \mathrm{PL}$ & $m u-/ n-$ & $-m u-/-n-$ \\
\hline CL.3 & $u-$ & $-m u-/-m-$ & $3 \mathrm{PL}$ & $v a-$ & $-v a-$ \\
\hline CL.5 & $l i-$ & $-u-$ & CL.4 & $i-$ & $-i-$ \\
\hline CL.7 & $c h i-$ & $-c h i-$ & CL.8 & $v i-$ & $-l a-$ \\
\hline CL.9 & $i-$ & $-i-$ & CL.10 & $d i-$ & $-d i-$ \\
\hline CL.11 & $l u-$ & $-l u-$ & & & $-t u-$ \\
\hline CL.12 & $k a-$ & $-k a-$ & CL.13 & $t u-$ & \\
\hline CL.14 & $u-$ & $-u-$ & & & \\
\hline CL.15 & $k u-$ & $-k u-$ & & & \\
\hline CL.16 & $p a-$ & $-p a-$ & & & \\
\hline CL.17 & $k u-$ & $-k u-$ & & & \\
\hline CL.18 & $m u-$ & $-m u-$ & & & \\
\hline
\end{tabular}


При этом показатель инфинитива усекается за счет начальной согласной. Таким образом, возможная полная морфемная формула инфинитива в ндонде представлена следующей моделью:

$$
\text { Pref }+\operatorname{Inf}_{1}+\operatorname{Inf}_{2}+\mathrm{R}+\text { Fin. }
$$

Для образования негативной формы оптатива выбирается иная стратегия, реализуемая в виде конфикса $-n a-\ldots-e$ :

(10) Nnalime.

n-na-lim-e

2PL-NEG-пахаTь-FIN

'Вы не должны / вам не следует пахать.'

\section{3. Максимальная структура глагольной словоформы}

Максимальная возможная структура глагольной словоформы следующая:

$$
\text { Pref }+\operatorname{Inf}_{1}+\operatorname{Inf}_{2}+\mathrm{R}+\mathrm{Suf}_{4}+\text { Prefin }+ \text { Fin }
$$

Простейшая финитная структура глагола в языке ндонде состоит из префикса, равного субъектному показателю, за которым следует аспектно-темпоральный аффикс, корень и финаль:

$$
\text { Pref }+\operatorname{Inf}_{1}+\mathrm{R}+\text { Fin }
$$

Например:

(11) Twaona mayembe.

Tu-a-on-a mayembe

1PL-PST-видеть-FIN мотыги

'Мы видели мотыги (и забыли об этом).'

Аффикс - $a$ - передает значение общего прошедшего времени безотносительно к последствиям действия. Состоящий из одной гласной, он вызывает ряд морфонетических изменений на стыке, таких как девокализация $(\mathrm{u}+\mathrm{a}>\mathrm{w})$ и слияние $(\mathrm{a}+\mathrm{a}>\mathrm{a})$. 


\section{1. Субъектные и объектные показатели}

В ндонде представлены субъектные показатели 1 и 2 лиц единственного и множественного числа и показателями 3 лица 18 именных классов. Глагольные показатели 1 и 2 лица ед. и мн. числа представляют собой более сложную систему как на уровне выражения, так и на уровне содержания. На формальных основаниях в эту же группу может быть введен показатель 3 лица ед. числа $a$-, так как он не является производным от префиксов-маркеров класса в отличие от других 17 субъектных показателей (Громова \& Охотина 1995: 274276). Субъектные и объектные показатели 3 лица остальных 17 классов в языке ндонде представляют собой трансформы маркеров именного класса (Громова \& Урб 2015).

\section{2. Аспектно-темпоральные показатели предкорневой позиции}

Материально не выраженная позиция $\operatorname{Inf}_{1}$ сигнализирует о нулевом показателе, который является маркером настоящего времени, обычного настоящего времени (хабитуатива), а также может передавать значение настоящего актуального времени:

(12) Tuyangata.

tu-Ø-yangat-a

1 PL-PRS-Помогать-FIN

'Мы [обычно] помогаем.'

(13) Valima.

va-Ø-lim- $a$

3PL-PRS-пахать-FIN

'Они [обычно] пашут.'

Эта же позиция $\operatorname{Inf}_{1}$ может быть представлена материально выраженными видо-временными показателями, например, маркером будущего времени без точной конкретизации временной дистанции: 
(14) Tunavalya.

tu-na-va-ly-a

1PL-FUT-3PL.OBJ-есть-FIN

'Мы съедим их (животных).'

Показатель -ni- репрезентирует значение перфектива, указывающего на то, что действие имело место в прошлом, но результат сохранился и в описываемый момент:

(15) Nninguhaulila.

n-ni-ngu-haulil-a

2PL-PFV-1SG.OBJ-говорить-FIN

'Вы сказали мне (и я услышал).'

Этому показателю свойственно также аспектуальное значение дуратива, т.е продолженности действия в прошлом:

\section{(16) Valume vanitongola chindonde. valume va-ni-tongol-a chindonde \\ мужчины 3PL-PRF-говорить-FIN язык.ндонде}

'Мужчины говорили на языке ндонде.' (в течение долгого времени)

Эту же позицию Inf 1 может занимать негативный показатель -ka-, как правило, относящий действие к настоящему моменту, но уточненный характер описываемого действия зависит от контекста:

(17) Nikalima mwadachi?
n-ka-lim-a
mwadachi
2PL-NEG-пахать-FIN
почему
'Почему вы не пашете?' (сейчас, в момент речи)

(18) Vakatuudya lido.

va-ka-tu-udy-a lido

3PL-NEG-1 PL.OBJ-спрашивать-FIN вчера

'Они нас не спрашивали вчера.' 
Значение прогрессива, передаваемое аффиксом -chi- ${ }^{3}$, показывает, что действие в прошлом находилось в процессе:

(19) Nchilima.

n-chi-lim-a

2PL-PROG-пахать-FIN

'Вы пахали.' (в какой-то момент в прошлом)

Позицию $\mathrm{Inf}_{2}$ между показателем лица/класса и объектным маркером может занимать показатель релятива -li-, который в некоторых контекстах (перед гласной) усекается до -l-:

(20) valitongolatongola

$v$-a-li-tongolatongol-a

3PL-PRS-REL-говорить.долго-FIN

'они, которые говорят долго'

(21) valudya

$v-a-l-u d y-a$

3PL-PRS-REL-спрашивать-FIN

'они, которые спрашивают'

Таким образом, предкорневые позиции в языке ндонде заняты субъектным показателем, аспектно-темпоральным или негативным показателем, за ними следует показатель релятива, затем объекта или рефлексива.

\section{3. Корень глагола}

Корень может подвергаться редупликации в сочетании с суффиксом и финалью, независимо от ее вокалического качества:

${ }^{3}$ Аффикс -chi- омонимичен дефектному глаголу -chi 'говорить'. По всей вероятности, в данном случае можно предположить грамматикализацию глагола -chi, выполняющего аспектно-темпоральную функцию. Такое явление свойственно многим языкам банту, ср.: в суахили -li 'быть' > -li- показатель прошедшего времени; в зулу -thi 'сказать' > ukuthi 'что' (союз); в кикуйю na ‘c, совместно' > -na- показатель настоящего времени. 
kutongol-a 'говорить' > kutongolatongola 'много/долго говорить'

vahimb-e 'пусть они копают' > vahimbehimbe 'пусть они копают глубоко/долго'

vahimb-ile ‘они копали' > vahimbilehimbile 'они копали глубоко/ долго'

\section{4. Деривативные суффиксы}

Суффиксальные позиции заняты деривативными глагольными суффиксами:

КАузАТив в языке ндонде выражается предфинальным суффиксом - $i$ - с возможной девокализацией в ряде контекстов:

-kuta кричать > -kut-i-a 'заставить кричать'

-tера 'сгибаться'> -tер-i-a 'сгибать'

-katapada 'быть красивым' > -katapad-i-a > katapadya 'делать красивым'

Форма ПАссивА в языке ндонде представлена морфемой -u-:

-lama 'исцелять' > -lam-и-a 'быть исцеленным'

-tера 'сгибаться'> -tер-и-a 'быть согнутым'

Морфологическим средством выражения АПпликАТиВА является суффикс -il- / -el-, образованный по закону сингармонизма (i, a, u в корне $>-i l$ - в суффиксе, e, o >-el-):

-himba 'копать' > -himb-il-a 'копать для кого-либо'

-tера 'сгибаться'> -tep-el-a 'сгибаться ради кого-то'

Односложные глаголы образуют аппликативную форму при помощи тех же суффиксов:

-pa 'нести фрукты' > -p-el-a 'нести фрукты для кого-либо'

-twa 'бить' > -tw-el-a 'бить кого-либо'

-lya 'есть'> -li-il-a 'сьесть за кого-либо' 
Категория стАТивА (нейтропассива) выражается посредством суффикса -ik-/ -ek- в соответствии с правилом сингармонизма:

-malila 'завершать' > -malil-ik-a 'быть в состоянии завершения' -sumisa 'продавать' > -sumis-ik-a 'быть продаваемым (можно продать)'

-lola 'смотреть / видеть'> -lol-ek-a ‘быть видимым’

Дериватема категории РЕципрокА представлена суффиксом -an-:

-lola 'смотреть' > -lol-an-a 'смотреть друг на друга' -lya 'есть'> -l-il-an-a 'есть друг друга'

Морфологическим средством выражения инТЕНСивА является суффикс -ang-:

-lola 'смотреть' > -lol-ang-a 'смотреть пристально'

-sumisa 'продавать' > -sumis-ang-a 'продавать активно'

«Обратная» форма, или РЕвЕРсив, выражается при помощи суффикса -ul-:

-chima 'закрывать'> -chim-ul-a 'открывать'

\section{5. Сочетание деривативных суффиксов}

Дистрибутивные возможности деривативных суффиксов представлены следующим образом:

1) статив + каузатив:

-lola 'смотреть/видеть' > -lol-ek-i-a > lolesia 'заставить быть видимым' (с чередованием $\mathrm{k}>\mathrm{s}$ );

2) реверсив + пассив:

-chima 'закрывать' > -chim-ul-w-a 'быть окрытым' (при вокализации суффикса пассива $-u$ - $>$ w);

3) аппликатив + пассив:

-lama 'исцелять' > -lam-il-w-a 'быть исцеленным ради коголибо’; 
4) аппликатив + каузатив:

-himba 'копать' > -himb-il-i-a > -himbidya 'заставить копать для кого-либо’ (с чередованием $1>\mathrm{d}$ и девокализацией i $>$ y);

5) пассив + реципрок:

-tama 'любить' > -tam-u-an-a 'быть любимыми друг другом';

6) пассив + аппликатив + каузатив:

-himba 'копать' > -himb-u-il-i-a > -himbwidya 'быть вскопанным для кого-либо’ (с девокализацией u $>$ w, чередованием $1>\mathrm{d}$ и девокализацией $\mathrm{i}>\mathrm{y})$.

Особое внимание следует обратить на случаи 5) и 6), в которых показатель пассива занимает первую суффиксальную позицию, что несвойственно другим языкам банту, в которых суффикс пассива замыкает деривативную цепочку, ср., например, в суахили -јиа 'знать' $>$-ju(a)-li-sh-w-a 'быть представленным' (аппликатив+каузатив+ пассив); в зулу -funda 'читать, учить' > -fund-is-el-w-a > 'быть обучаемым кем-то’ (каузатив + аппликатив + пассив); в курия -hinca 'готовить' > -hinc-er-w-a 'быть приготовленным для кого-либо' (аппликатив + пассив).

\section{6. Аспектно-темпоральные показатели В посткорневой позиции}

К числу суффиксов относится показатель перфекта -ile / -e, обозначающий полную завершенность действия:

-himba 'копать'> tu-himb-ile 'мы уже выкопали'

kulilima 'пахать его (поле)' > li-lim-u-il-i-e > li-limwidy-e 'оно (поле) уже вспахано’

Омонимичный суффикс -е выражает значение оптатива с модальными признаками:

-udya 'спрашивать' > tu-mu-udy-e 'давайте спросим его'

-viisa 'сердиться'> u-na-viis-e 'тебе не следует сердиться' 


\section{4. Заключение}

Анализ системы глагола в языке ндонде носит предварительный характер. В статье отмечены лишь основные параметры глагольных категорий, таких как: субъектно-объектные местоименные показатели, аспектно-темпоральные и модальные маркеры, категория релятива, деривативные суффиксы и их сочетаемость. В целом эти данные не противоречат «бантускому канону», хотя и встречаются определенные отклонения от него, в частности, в комбинациях деривативных суффиксов. Эти особенности языка ндонде позволяют в определенной мере сохранить для бантуистики и африканского языкознания аутентичный материал языка, находящегося на грани исчезновения, и продемонстрировать отличительные черты ндонде в типологическом ракурсе.

\section{Приложение. Текст на языке ндонде}

Текст на языке ндонде

Nguta, Kadimu na Inyoonda ${ }^{4}$

1) Nguta na Kadimu vanikwikala paimo kumachinga. 2) Liisiku liimo Inyoonda na michila mivili apitile paweelu akavaonile. 3) Inyoonda nkuimba5 luhimu. 4) Nguta amupilikanile nkuchi Kadimu: tumulange na kumulya. 5) Kadimu nkuitikila ninamteleka utokoote chinduule kadiki tunailya chiihi. 6) Viino Inyoonda nyambone aheka avalambile aphanda pamlandi mnnehu atikisa na michila mivili.

4 Тексты на языке ндонде были записаны авторами от информанта Мохамеда Селемани Чидо (70 лет), уроженца деревни Нкунья в окрестностях города Мтвара во время полевого исследования в Танзании.

5 При выражении последовательности действий в нарративе 3 лицо ед. числа реализуется в форме $n$ - в сочетании с инфинитивным показателем - $k u$-, что в переводе соответствует деепричастию или неопределенно-личной форме соответствующего глагола в прошедшем времени. 


\section{Глоссированный текст}

1) Nguta na Kadimu va-ni-kwikala pa-imo ku-ma-chinga. 9СL.гиена и/с 9СL.слон 3PL-PFV-жить 16CL-один 17CL-6CL-гора 'Гиена и Слон жили вместе в горах.'

2) Li-isiku li-imo Inyonda na mi-chila mi-wili 5CL-день 5CL-один 9СL.обезьяна и/с 4CL-хвост 4CL-два 'Однажды Обезьяна двухвостая ... a-pit-ile pa-weelu

3SG-идти.мимо-PRF 16CL-5CL.поле

... проходила недалеко, a-ka-wa-on-ile.

3SG-NEG-3PL.OBJ-видеть-PRF

... она их не видела.'

3) Inyonda n-kuimba lu-himu

9сL.обезьяна 3sG-петь 11CL-песня

'Обезьяна пела песню.'

4) Nguta a-mu-pilikan-ile n-kuchi Kadimu 9СL.гиена 3sG-3SG.OBJ-слышать-PRF 3sG-говорить 9СL.слон 'Гиена услышала её, она сказала Слону: tu-mu-lang-e na ku-mu-lya 1PL-3sg.oBJ-хватать-OPT и 15CL-3sG.оBJ-есть «Давай мы схватим её и съедим её!»'

5) Kadimu n-kuitikila ni-na-m-teleka 9СL.слон 3SG-отвечать 1sG-FUT-3SG.OBJ-готовить/жарить 'Слон ответил: «Я приготовлю её, u-tokoot-e chi-nduule kadiki tu-na-i-lya chiihi 2SG-варить-оPT 7CL-овощ немного 1PL-FUT-9CL-есть сразу ... ты свари немного овощей, мы съедим её (еду) сразу.'

6) Viino Inyonda ny-ambone a-heka тут 9СL.обезьяна 9CL-умный 3SG.PST-смеяться ‘Тут умная Обезьяна рассмеялась, ... 
a-va-lamb-ile

3SG-3PL.OBJ-обманывать-PRF a-phanda

3SG.PST-влезать

...она обманула их, она влезла ...

pa-m-landi m-nnehu a-tikisa na mi-chila mi-vili

16CL-3CL-дерево 3CL-высокий 3SG.PST-махать с 4CL-хвост 4CL-два ... на высокое дерево и помахала двумя хвостами.'

\section{Литературный перевод \\ Гиена, Слон и Обезьяна}

Гиена и Слон жили вместе в горах. Однажды двухвостая Обезьяна проходила недалеко, она их не видела. Она пела песню. Гиена услышала ее и говорит Слону: «Давай мы ее схватим и съедим». Слон отвечает: «Я приготовлю ее, ты свари немного овощей и мы сразу ее (еду) съедим». Умная Обезьяна рассмеялась, она их обманула, влезла на высокое дерево и помахала двумя хвостами.

\section{Сокращения}
CL - именной класс
FIN - финальный гласный
FUT - будущее время
NEG - показатель отрицания
овJ - объектный показатель
ОРТ - оптатив
PFV - перфектив
PL - множественное число

$$
\begin{aligned}
& \text { PRF - перфект } \\
& \text { PROG - прогрессив } \\
& \text { PRS - настоящее время } \\
& \text { PST - прошедшее время } \\
& \text { R - корень } \\
& \text { REL - релятив } \\
& \text { SG - единственное число } \\
& \varnothing-\text { нулевая морфема }
\end{aligned}
$$

\section{Литература}

Аксенова, И.С. 2003. Глагол в языках банту. В кн. Виноградов, В.А. \& Топорова, И.Н. (ред.), Основы африканского языкознания, 41180. М.: Восточная литература.

Аксенова, И.С. \& Топорова, И.Н. 1990. Введение в бантуистику. Имя. Глагол. М.: Наука. 
Виноградов, В.А. \& Топорова, И.Н. (ред.). 2003. Основы африканского языкознания. Глагол. М.: Восточная литература.

Громова, Н.В. \& Охотина, Н.В. 1995. Теоретическая грамматика языка суахили. М.: Наследие.

Громова, Н.В. \& Урб, М.Р. 2015. Именные классы языка ндонде (по материалам полевого исследования). Вестник Московского университета. Серия 13. Востоковедение 2. 12-20.

Громова, Н.В. \& Урб, М.Р. 2019. Влияние языка суахили на местные языки банту в современной Танзании. Вестник Московского университета. Серия 13. Востоковедение 2. 20-34.

Поздняков, К.И. 2017. Славянские счетные существительные на фоне бантуских именных классов. В кн. Выдрин, В.Ф. \& Ляхович, А.В. (ред.), В желтой жаркой Африке. К 50-летию Александра Желтова, 158-170. СПб.: Нестор-История.

Atlasi ya lugha za Tanzania [Atlas of languages of Tanzania]. 2009. Dar es Salaam: Chuo Kikuu cha Dar es Salaam.

Bastin, Yvonne. 1978. Les langues bantoues. In Barreteau Daniel (ed.), Inventuaire des études linguistiques sur les pays d'Afrique noire d'expression française et de Madagascar, 123-185. Paris: Conseil international de la langue française.

Doke, Clement M. 1935. Bantu linguistic terminology. London: Longmans. Guthrie, Malcolm. 1948. The classification of the Bantu languages. London: Oxford University Press.

Maganga, Clement \& Schadeberg, Thilo. 1992. Kinyamwezi: grammar, texts, vocabulary. Köln: Rüdiger Köppe.

Nurse, Derek. 1972. A phonological and morphological sketch of 15 of the principal languages of Tanzania. Dar es Salaam: Institute of Kiswahili Research, University of Dar es Salaam.

\section{References}

Aksenova, Irina S. \& Toporova, Irina N. 1990. Vvedenie v bantuistiku. Imja. Glagol [Introduction into Bantu studies. Noun. Verb]. Moscow: Nauka. Aksenova, Irina S. 2003. Glagol v jazykax bantu [Verb in Bantu]. In Vinogradov, Viktor A. \& Toporova, Irina N. (eds.), Osnovy afrikanskogo jazykoznanija, 41-180. Moscow: Vostočnaja literatura. 
Atlasi ya lugha za Tanzania [Atlas of languages of Tanzania]. 2009. Dar es Salaam: Chuo Kikuu cha Dar es Salaam.

Bastin, Yvonne. 1978. Les langues bantoues. In Barreteau Daniel. Inventuaire des études linguistiques sur les pays d'Afrique noire d'expression française et de Madagascar, 123-185. Paris: Conseil international de la langue française.

Doke, Clement M. 1935. Bantu linguistic terminology. London: Longmans. Gromova, Nelli V. \& Oxotina, Natal'ja V. 1995. Teoretičeskaja grammatika jazyka suaxili [A theoretical grammar of Swahili]. Moscow: Nasledie.

Gromova, Nelli V. \& Urb, Monika R. 2015. Imennye klassy jazyka ndonde (po materialam polevogo issledovanija) [Noun classes in Ndone (based on field data]. Vestnik Moskovskogo universiteta. Serija 13. Vostokovedenie 2. 12-20.

Gromova, Nelli V. \& Urb, Monika R. 2019. Vlijanie jazyka suaxili na mestnye jazyki bantu v sovremennoj Tanzanii [Swahili influence on the local Bantu languages in modern Tanzania]. Vestnik Moskovskogo universiteta. Serija 13. Vostokovedenie 2. 20-34.

Guthrie, Malcolm. 1948. The classification of the Bantu languages. London: Oxford University Press.

Maganga, Clement \& Schadeberg, Thilo. 1992. Kinyamwezi: grammar, texts, vocabulary. Köln: Rüdiger Köppe.

Nurse, Derek. 1972. A phonological and morphological sketch of 15 of the principal languages of Tanzania. Dar es Salaam: Institute of Kiswahili Research, University of Dar es Salaam.

Pozdniakov, Konstantin I. 2017. Slavjanskie sčetnye suščestvitel'nye na fone bantuskix imennyx klassov [Slavonic numerative nouns against the background of the Bantu noun classes] In Vydrin, Valentin F. \& Lyakhovich, Anastassia V. (eds.), V̌̌eltoj žarkoj Afrike. To Aleksander Zheltov's 50 th birthday, 158-170. St. Petersburg: Nestor-Istorija.

Vinogradov, Viktor A., \& Toporova, Irina N. (eds.). 2003. Osnovy afrikanskogo jazykoznanija. Glagol [Essentials in African linguistics. Verb]. Moscow: Vostočnaja literatura. 